\title{
Breaking the barrier of service hostility: A lean approach to achieve operational excellence
}

\author{
Mofizul Islam Awwal \\ MIP School, Politecnico di Milano, Milano, Italy \\ Email address: \\ mofizulislam.awwal@mail.polimi.it
}

\section{To cite this article:}

Mofizul Islam Awwal. Breaking the Barrier of Service Hostility: A Lean Approach to Achieve Operational Excellence. International Journal of Business and Economics Research. Special Issue: Supply Chain Management: Its Theory and Applications. Vol. 3, No. 6-1, 2014, pp. 65-73. doi: $10.11648 /$ j.ijber.s.2014030601.20

\begin{abstract}
Due to globalization industries are rapidly growing throughout the world which leads to many manufacturing organizations. But recently service industries are beginning to emerge in large numbers almost in all parts of the world including some developing countries. In this context organizations need to have strong competitive advantage over their rivals to achieve their strategic business goals. Manufacturing industries are adopting many methods and techniques in order to achieve such competitive edge. Over the last decades manufacturing industries have been successfully practicing lean concept to optimize their production lines. Due to its huge success in manufacturing context lean has made its way into the service industry. From past literature it has been observed that there hasn't been any significant research development of lean applicability for service industry. In fact very little importance has been addressed to service in the area of operations management. Service industries are far behind than manufacturing industries in terms of operations improvement. It will be a hectic job to transfer the lean concept from production floor to service back/front office which will obviously yield possible improvement. Service processes are not as visible as production processes and can be very complex. Lack of research in this area made it quite difficult for service industries as there are no standardized frameworks for successfully implementing lean concept in service organization. The purpose of this research paper is to capture the present scenario of service industry in terms of lean implementation. Thorough analysis of past literature will be done on the applicability and understanding of lean in service structure. Classification of research papers will be done and critical factors will be unveiled which leads to a conceptual framework for implementing lean in service industry to achieve operational excellence.
\end{abstract}

Keywords: Lean Service, Lean Literature Classification, Lean Implementation, Service Industry, Service Excellence

\section{Introduction}

Burnes has pointed out the fact that there are several managerial practices throughout different industries and an evolution is taking place within those managerial practices over the period of time [1]. Therefore managers within the organizations need to cope up with the updated management principles to achieve their organizational goals. In order to increase the efficiency of the business operation many industries are adapting various popular managerial practices to produce competitive operations strategy which will give them the necessary boost in the market over other competitors [1], [2]. In this way they are moving away from their traditional way of thinking and worn out strategies. Many organizations are facing difficulties in gaining operational excellence and competitive edge over their competitors. As a result numerous organizations are implementing lean methodology to achieve operational excellence which will lead to perfection. In present days lean is such a popular managerial practice which enables organizations to increase their efficiency and effectiveness by eliminating non value adding activities from their organizational processes. Many scholars have urged organizations to implement lean concept for enhancing their capabilities [3].

Womack, Jones and Roos have mentioned that there is a rise in popularity in lean tools and techniques among various companies because of its success stories in many organizations in Japan [4]. Mr Kiichiro Toyoda along with Mr. Taiichi Ihno first discovered the lean methodology in the field of manufacturing industry by keeping their focus on eliminating wastes within the production process [5]. Despite 
its origin of development lean has invaded other type of industries with its unique characteristics including service organizations. The focus on service industries has been increasing day by day as service industries are contributing much more than the manufacturing industries within the whole economy. Although there is immense potentiality of lean application in the service context, organizations are not utilizing this effective methodology like the way they should be [6].

Service managers have not utilized the superiority of lean principles within the service industries to get the best out of it because of the fact that lean has been originated from the manufacturing context and thus service managers have avoided the opportunity to improve their overall productivity [7]. Many scholars have identified numerous advantages for implementing lean methodology within manufacturing industry but recently researchers have observed the applicability of lean concept within any kind of industry. For instance, healthcare sector, educational sector, financial sector have utilized this revolutionary concept to achieve higher customer satisfaction through increased productivity and efficiency.

Although scholars have been urging the managers to implement lean within their service organizations, there have been very less amount of progress in the application of lean methodology within the service context. Sarkar [8] has mentioned about the lack of knowledge regarding lean applicability carried out by the managers as there have not been any significant amount of research development in the area of lean service. The little number of studies made within the research area of lean service did not make very convincing framework as application of lean tools and techniques have not been made very clear to the managers within the service industry. Therefore to make the implementation process of lean methodology clear to everyone, this paper will undergo a thorough review of literature related to lean production, service management, lean service and will try to establish a conceptual framework based on previous relevant research papers.

An attempt will also be made to explore different kinds of lean tools and techniques as well as the possible obstacles for implementing them. In the process of developing theoretical framework numerous research papers will be thoroughly studied for the purpose of producing a classification of those articles which will help the author to identify various critical factors for implementing lean methodology within service environment.

\section{Three Phase Review Process}

Reviewing literature is indeed a difficult task to complete without the assistance of various analytical tools. There are many tools and methodologies available for analyzing numerous scientific articles written by many scholars. Among many methodologies systematic review methodology (SRM) [9] has been selected to scrutinize various scientific papers and articles from different authenticate sources. SRM has been widely used by many scholars for getting the in depth analysis of research papers all over the world. The reason behind its popularity lies within its characteristics which enable the researcher to review in a very systematic way, with proper scientific explanation and can give the researcher a clear idea with its transparent way of reviewing scientific papers. The whole review process was conducted into three phases which are described below:
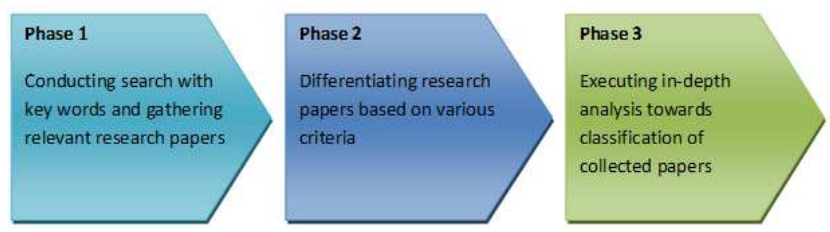

Figure 1. Three phase review process

At first few key words were selected based on the main research topic of this dissertation. These are "lean service", "lean service operation" and "lean service excellence". These key words have been inserted into the search engine of some reputed databases of scientific research paper and a thorough search was conducted based on those words. These databases include Heriot-Watt University's online library, Emerald Insight, Taylor \& Francis online database, Scopus and Science Direct. All the research papers were strictly scrutinized based on their research title, abstract and key words within the paper, which came out after the execution of search. Those which have been selected for their strong relevance with the dissertation topic, exploited further in their reference section for finding out further relevant research paper which may show strong resemblance with the research focus. Approximately 141 research papers were found after repeating the searching process over and over again in the above mentioned databases and thus completing the phase 1 as shown in Fig. 1.

After gathering all the relevant research papers the toughest part of the process began. An intensive reading has been done very carefully for each and every research paper which was found to be in line with the research topic. Every valuable observation has been noted from the thorough reading for further necessary analysis. An effort has been executed to identify different categories or segments of those research papers based on different aspects, such as: methodology of research, concentrated industry, evolution of lean throughout the time frame, utilized lean techniques, reasons for implementing lean, obstacles faced and findings of the research conducted.

The third and final phase of this review process is the most interesting compared to the other two phases. It involves analysis of the gathered information from the selected research papers. A list has been created in MS Excel to put all the necessary data in one worksheet. Several Columns have been created to categorize the papers in a single worksheet. These columns are: year of publication, title of the paper, author name, name of the journal, methodology used in research, focused industry etc. Numerous graphs were created for better understanding of the analysis which helped the 
author to scrutinize further into the research area.

\section{Evolution of Research in Lean Service}

From Fig. 2 it can be observed that there have been many research developments over the period of time in the field of lean service and especially from 2005 the number of publications has drastically increased till today. As showed in Fig. 2 there is a rise of publication regarding lean service in the year 1995. The reason behind this surprising peak is that most of the articles published in the year 1995 have emphasized their research in the education service industry. The most number of articles in line with lean service research area was published in the year of 2013. Also the small number of publication showed in the year of 2014 is because the year hasn't been finished yet. The way these researches have been progressing in lean service, it is obvious that the number of publication will surpass the previous year's record by a big margin. Out of these 141 articles staggering $16 \%$ of them were published in 2013 as shown in Fig. 3. This is the proof of growing research development of lean methodology in the service context. Also from the Fig. 3 it can be seen that $12 \%$ and $11 \%$ of the total articles were published in the year 2012 and 2011 respectively. The Fig. 3 shows a gradual development of research in the area of lean service.

\section{Publications over time}

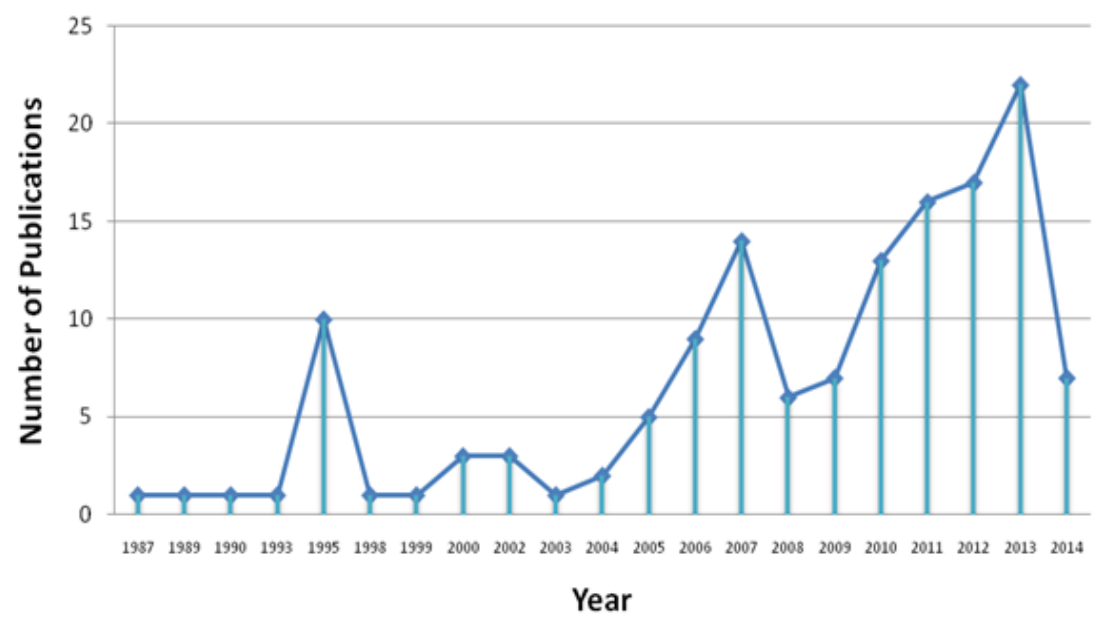

Figure 2. The development of number of publications over time

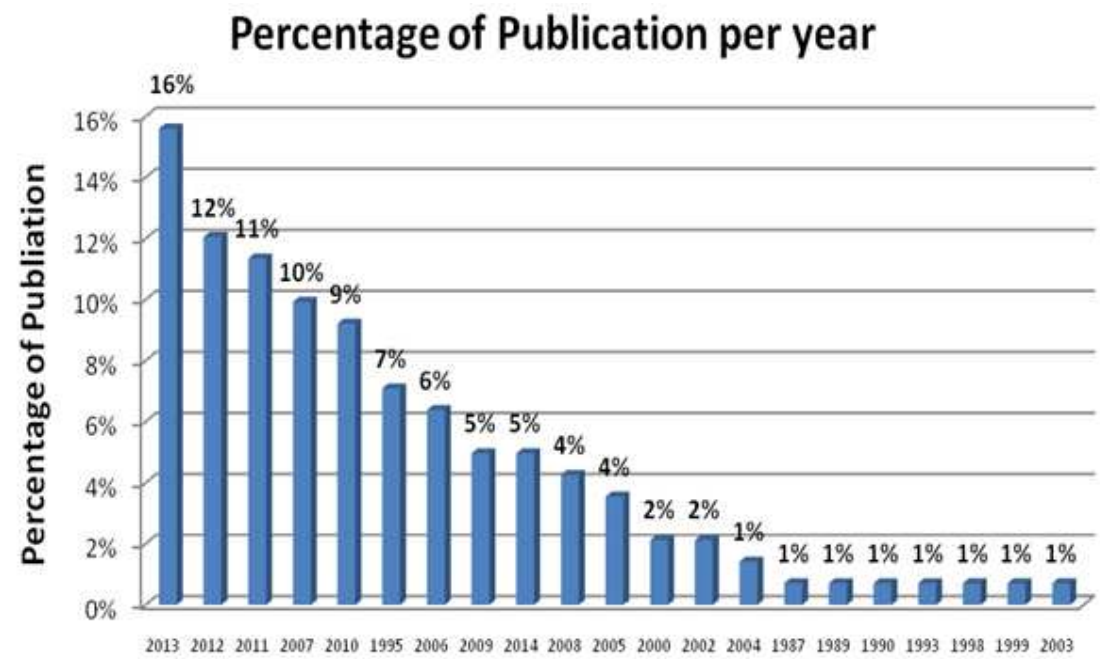

Figure 3. Percentage of research publication per year

\section{Research Tools and Techniques}

Fig. 4 illustrates various kinds of methodologies followed by different scholars to conduct their research in the area of lean service. The most practiced methodology among them according to the Fig. 4 is the case study. After that literature review and conceptual are the two most utilized research methods compared to the rest of the methodologies. The case study method has been used by 66 research articles whereas literature review and conceptual methods have been used by 34 and 18 articles respectively. It has also been observed that the method of survey was used comparatively in low frequency which by the way is a very important tool to carry out research activities. 
These are the research tools and techniques used by different researchers over the period of time:

- Case Study

- Literature Review

- Conceptual

- Survey

- Multiple Cases

- Simulation

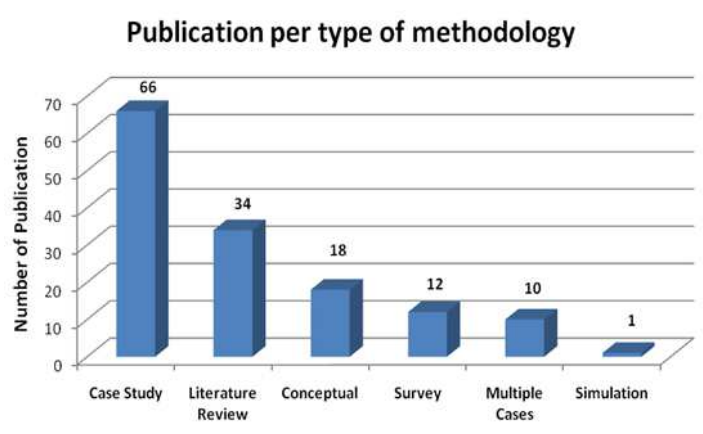

Figure 4. Number of publications per type of methodology

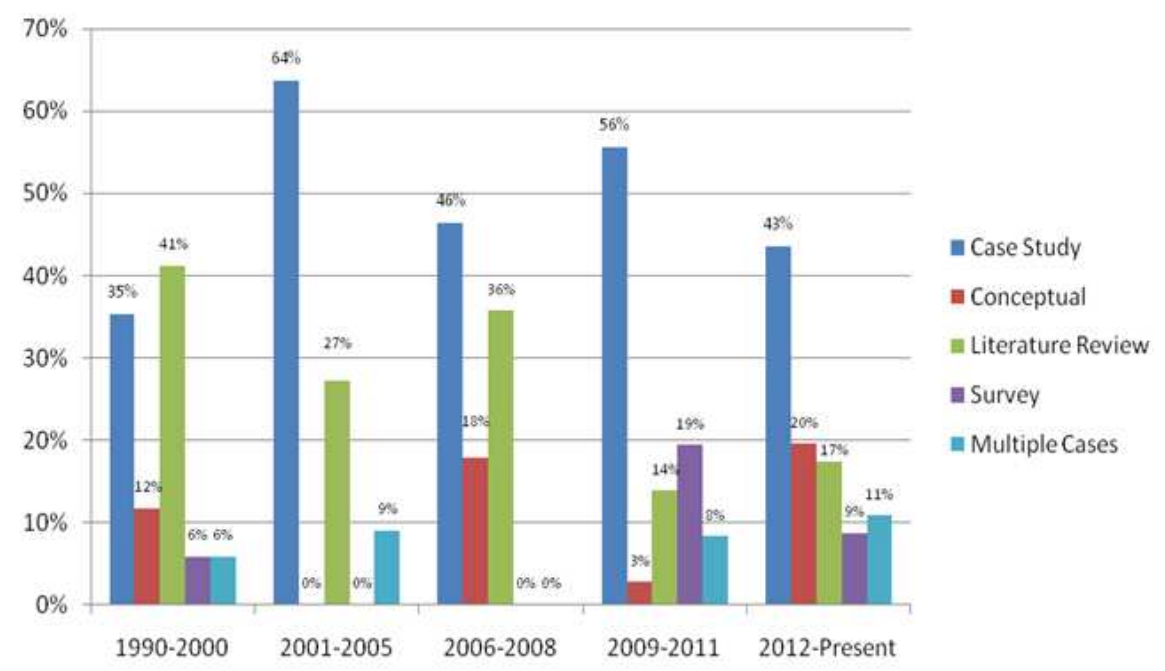

Figure 5. Different Research tools over period of time

From Fig. 5 it can be seen that among various research tools, case study method has been practiced more than any other research methods. From 1990 to 2000 literature review was used more than case study method as at that time scholars were trying to explore the field of lean service with their logics and opinions. From 2001 to 2005 only case study method was found to be dominating over other methods as $64 \%$ research articles utilized the case study method to express their opinions. Between the year of 2006 and 2008, case study and literature review were the significant research methods used by different scholars.

From 2009 case study method was becoming the popular method to conduct research compared to other available research tools and techniques. From 2012 other research tools were crawling back as many researchers have utilized other tools like: multiple cases, survey and conceptual method.

\section{Lean Service in Various Service Contexts}

Fig. 6 illustrates various kinds of service industries with respect to the number of publications. About 14 service sectors have been identified through strong analysis from a total of 141 research articles. Among them healthcare service got the most attention of the author as 39 scientific articles have researched about lean service in the healthcare service sector. The healthcare service has been successfully implementing lean concept with strong precision over the time and now a day's many hospitals have also started the process of transforming their organization according to the lean principles. This has been a wonderful success story for the healthcare service as the number of research is gradually increasing over the period of time in the area of lean service. Also governmental service, education service and financial service have been involved in the lean transformation process.

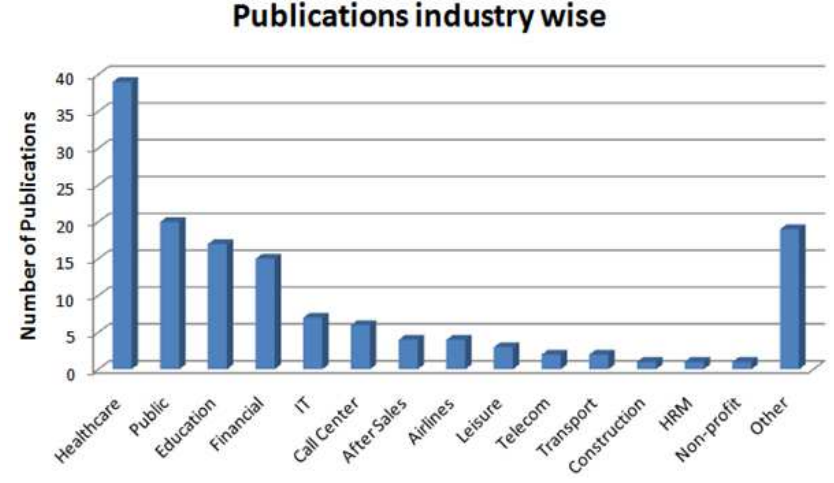

Figure 6. Number of publication in different type of service industries

From Fig. 6 one can also observe the variability of service industry, which means service industries are trying to break the shackle of their conventional way of thinking. Although 
service processes are very much complex in structure and they are hard to maintain with variable customer demand, but many success stories of lean application has made the organization much more eager to implement this concept. This figure proves the fact that lean implementation is not the only success story of production system but also the success story of service system as well. The author was unable to detect specific industry in 19 research articles as those were written by targeting the overall service industry.

There is another noticeable point which needs to be mentioned. The implementation of lean concept has shown its existence over many kinds of service industry, but very few researchers have shown their interest in the after sales service sector. It is indeed a well known fact that lean concept is well established in the manufacturing industry and normally most of the manufacturing industries will have their after sales support or service.

Progress of various service sectors over time

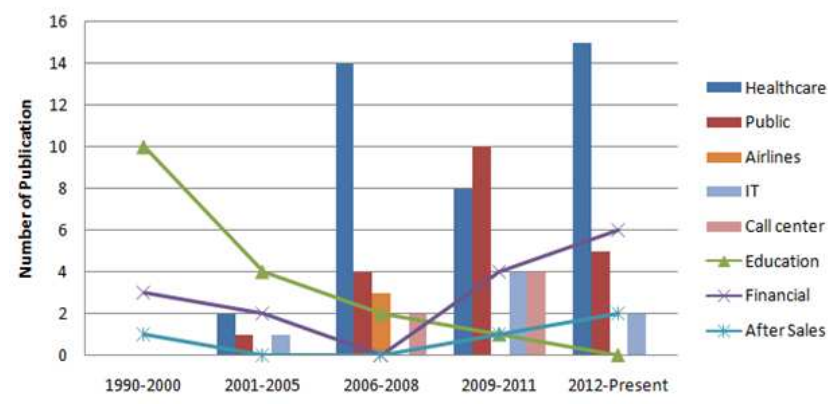

Figure 7. Research progress of various service sectors over time

As lean concept has originated from the automotive industry, almost all western automotive manufacturers have established lean methodology very successfully. Moreover every automotive manufacturer has their after sales service workshops to support the customers during the product consuming process. But surprisingly there have been very negligible amount of research conducted in the automotive service sector. The author failed to find any research article which successfully implemented lean concept in the automotive after sales industry. As there are a huge number of automotive manufacturers in the market, researchers should focus on establishing lean concept in the automotive service industry. From Fig. 7 one can see that there are hardly any researches conducted in after sales service sector. Also there hasn't been any research development in the education service sector as the line representing the education service has fallen down over time in Fig. 7. Moreover from the year 2000 researchers have emphasized on the public service industry as the number of publication is growing year by year.

In Fig. 8 a clear picture has been illustrated regarding shifting of research focus in various service sectors. From the year of 1990 to 2000 researchers have shifted their focus from financial to education industry. They have kept their focus on education industry from 2001 to 2005. From 2006 to 2008 more researches were conducted on healthcare industry and then from 2009 to 2011 they have emphasized more on public service sector keeping the healthcare industry below. But again from 2012 healthcare industry was able to capture the attention of the researchers.

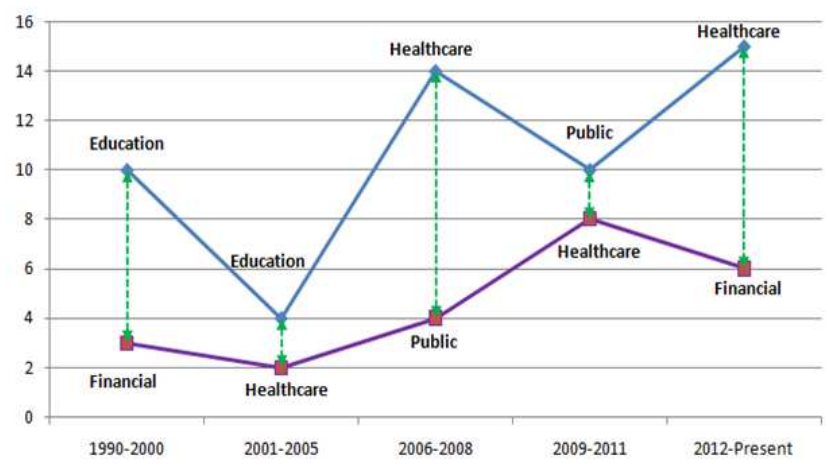

Figure 8. Shifting of research focus over time in service industries

\section{Classification of Research Papers}

Total 141 research articles were thoroughly analyzed for identifying different categories. After careful analysis the author decided to divide all the research papers into three categories following similar classification made by Suarez Barraza, Smith and Dahlgaard-Park [10].

As shown in Fig. 9 the three categories are:

\subsection{Exploration}

This type of research paper mainly focused on establishing strong justification for implementing lean methodology in the service industry. Many articles have structured concrete opinions about the applicability of lean in service sector. Mostly authors of these papers have contributed greatly to make the reader understand the fact that it is very much possible and promising to establish lean principles in various service industries. Many articles do not have direct connection of lean implementation and one can confuse these papers as irrelevant to the research topic, but if analyzed deeply readers can find that these papers are the pillars behind the initiation of lean application in service.

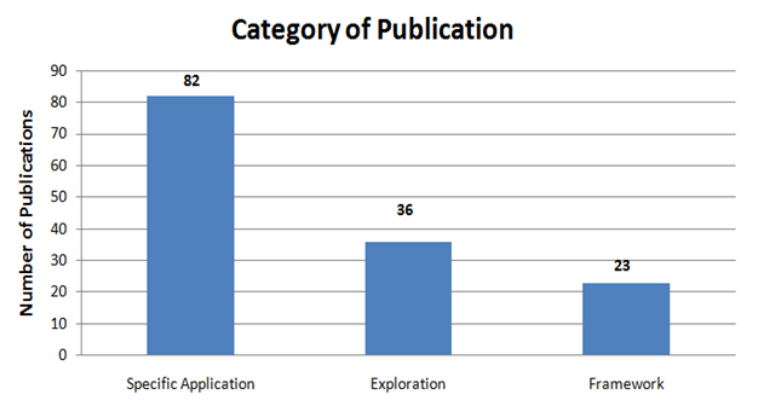

Figure 9. Categories of total 141 research paper

\subsection{Framework}

Many scholars have tried their best to develop further improved model for lean applicability. They have also tried to develop a suitable service structure in which normal lean 
principles will adapt very easily. The concept of this lean service came out first in the 1990's and many researchers even making negative comments as they thought it will not adjust with the complex service process and the high variability of customer demand. Bowen and Youndahl (1998) were the first one to present the concept of lean service in a form of a scientific paper. They have also supported their opinions by projecting successful lean cases like: McDonalds, Southwest Airlines and Taco Bell. After that over the period of time many researchers have involved themselves to develop many model or frameworks which will help the organizations to transform their regular process into lean process.

\subsection{Specific Application}

This type of research paper generally describes the successful implementation process within an organization through a single case study or multiple case studies. By specific it means these papers concentrated directly into a specific service industry, like: healthcare, financial, public, education, after sales, airlines, leisure, transport, construction etc. The importance of these scientific papers is immense in this research area. Because the more they initiate invading into different service sector the more will be the possibility to implement lean concept into those industries.

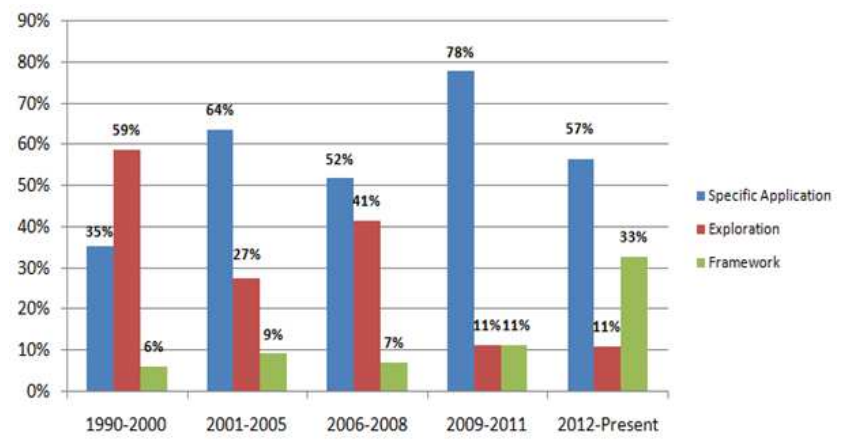

Figure 10. Progress of different categories of publication over time

Fig. 10 shows the time line progress of three categories of the research papers. Over the period of time scientists have focused more on specific service industries. As the time goes by the specific application articles have increased gradually. As usual exploration category articles possess $59 \%$ of the total articles published within 1990 to 2000 . The reason behind this is the newly introduced lean method in the service arena. But after 2001 every researcher has focused more on a specific sector for lean transformation. As scholars have scrutinized enough in the lean service area the numbers of exploration articles have begun to decrease. But till 2011 researcher were unable to define a concise framework for implementing lean in the service sector. As a result the number of articles in the framework category is very less. But from 2012 they have started to develop lots of framework based on past research and thus the number is increasing. Although the number has increased in framework category researchers still didn't able to discover a standard framework for the overall service industry for lean transformation. After analyzing most of the service sectors following factors have been identified:

Table 1. Critical enablers for lean service

\begin{tabular}{ll}
\hline Service Industry & Enablers \\
\hline & Customer focused process [11]. \\
Healthcare & High standard of quality [11]. \\
& High level of commitment [12]. \\
& Strong leadership, training [13]. \\
& Customer focused process [14]. \\
& High level of commitment [14], [15]. \\
& Continuous improvement/Kaizen [15]. \\
Education & Cross-functional activity [16]. \\
& High standard of quality [15]. \\
& Innovation [17]. \\
& Standardizing procedures, Segregating \\
& complexity, Posting performance results, Placing \\
Financial & linked processes closer [18]. \\
& Standardizing procedures [19]. \\
Airlines & Customer focus, involvement and training [20]. \\
& Continuous Improvement [21]. \\
Public & High standard of quality [22]. \\
& Standardizing procedures [21]. \\
Leisure & High standard of quality [10]. \\
\hline
\end{tabular}

Table 2. Critical disablers for lean service

\begin{tabular}{ll}
\hline Service Industry & Disablers \\
\hline \multirow{3}{*}{ Healthcare } & Unwillingness to change [23]. \\
& Lack of resource [23]. \\
& Overlapped processes [13] \\
& Lack of team synergy [24]. \\
& Unable to detect actual customer requirement \\
& {$[24]$.} \\
Education & Uncoordinated tutoring [25]. \\
& Biased focus on Administration rather than \\
& academic [26]. \\
Financial & Unorganized process [18]. \\
Airlines & Unorganized process [27]. \\
& Narrow division of labor [20]. \\
& Lack of commitment from senior management, \\
& change objectives that are not aligned to \\
customer requirements, a lack of training for \\
Public
\end{tabular}

\section{Conceptual Framework}

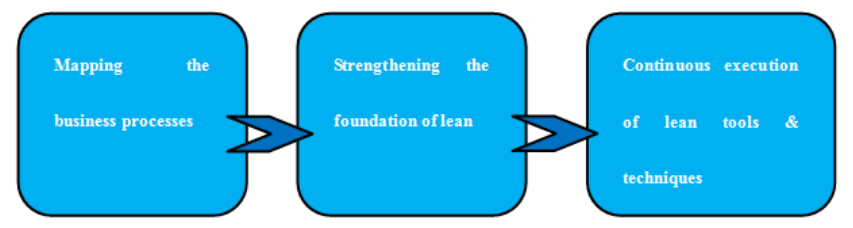

Figure 11. Conceptual framework for implementing lean principles

Weick and Quinn [31] have explained their model for continuous change. They are the two pioneers in the field of organizational change theory. Now-a-days organizations have to cope up with the continuous change in order to generate competitive advantage. Weick and Quinn [31] have mentioned an effective model for implementing change within organizations which is: Freeze-Rebalance-Unfreeze. Following the same methodology the author decided to 
develop a conceptual framework for implementing lean principles within service organizations.

\section{Conclusion}

Due to globalization fierce competition has emerged within the market and has driven various industries to implement numerous innovative managerial practices in order to eliminate wastes as well as downsize expenditure. Among various managerial methods lean is such a concept which has the ability to assist managers to eliminate non value added activities from the organizational processes by implementing dynamic change tools and focuses on excellence in operation to achieve high customer satisfaction index. Lots of manufacturing organizations have enjoyed the privilege of achieving operational and financial performances by adopting lean methodology over non adopting organizations. It is obvious that lean concept hasn't been considered in the same way in the service context as it was in manufacturing industry. However service industries are starting to adopt lean methodology within their organizational structure after many success stories among various service sectors. Many researchers have explored in the area of lean service to investigate the validity of lean in service context through different research methods like: case study, conceptual, survey, multiple cases and literature review. Moreover many service industries have started to implement this ground breaking concept to achieve operational excellence.

To get the present scenario of service industry one has to identify different service sectors available in the market. There are many types of service industries operating their business like: healthcare, public, financial, educational, call centre, after sales and many more. After analyzing a total of 141 research articles it has been found that most of the service industry has been practicing the lean service concept. However healthcare service industry has more dominance over other service sectors in terms of lean transformation. Researchers have focused more on healthcare service over other types of service industry. Also healthcare industry has been continuing this progress over the period of time. The research progress in the area of lean service has been growing gradually in the healthcare industry. Besides healthcare industry public service has progressed over the period of time. But after sales and education service haven't been able to grab much attention as researches in these industries have been decreasing over time. There haven't been significant amount of research development in lean service in leisure, airlines and call center industry. Moreover researchers mostly used case study method to conduct their researches to validate the lean concept in service industry. Conceptual and literature review method were moderately used by various authors. The multiple cases method was used in low numbers but the number is growing over time. One of the effective ways for conducting research is the survey method and very few scholars have utilized it to exploit the lean service concept.

In order to differentiate the research articles in the area of lean service, the author has scrutinized all of 141 articles and finally classified them according to three categories, which are: exploration, framework and specific application. These three categories are best suited for all the research articles in line with lean service concept. Among these three types of articles, specific application articles are high in number compared with the other two types. Over the time researchers have emphasized on specific service industry and the number of publication in this category is growing year by year. Exploration articles were mostly published in the early 1990's when scholars were trying to establish the lean concept in service industry. Very few were found in framework category as there hasn't been any standard framework developed for implementing lean in service industry.

There are various factors which enable as well as disable organizations to adopt lean within their business process. It is very important to identify these factors which will assist the organization to implement lean successfully. Author of this thesis has identified various factors which will help organizations to be proactive in implementing lean principles successfully in their respective service industries.

\subsection{Major Findings}

- There has been lack of empirical or survey research in the field of lean service to clarify the logic behind conceptual framework for implementing lean.

- The research progress in the area of lean service is growing gradually over the period of time.

- A wide range of service industries have involved them with the lean service concept and new service sectors are getting involved to achieve operational excellence.

- Healthcare service sector has been emphasized more than any other service industries for implementing lean concept.

- After sales service industry has received less attention from researchers compared to its vast presence in the market.

- Most of the researchers have utilized case study method to conduct their respective investigations in the area of lean service irrespective of the type of service.

- In recent years public and financial service industries have been drawing attention to the researchers in terms of lean transformation.

- Authors have been focusing more on specific service industry rather than emphasizing on the whole service sector and this progress is radically increasing year by year.

- Lean service is more of a strategic approach which places its client in the center of organizational processes.

- Lean service not only brings change in organizational structure but also brings change in employee's way of thinking.

- The effort for developing a standard framework for implementing lean concept in service is growing rapidly over time.

- Till now there haven't been any standard framework developed for implementing lean effectively and efficiently in service industry. 


\subsection{Future Research Provisions}

- Researchers can develop conceptual theoretical framework for implementing lean method in the service context based on the identified critical enablers and disablers from this thesis which will lead towards operational excellence.

- Scholars can integrate qualitative models with quantitative studies to generate more concrete conclusions to support their opinions.

- Researchers can further analyze the characteristics, principles, tools and techniques of lean thinking in the healthcare industry to validate whether it is lean service or any other unknown model which is only suitable for healthcare industry.

- Researchers can mix different managerial concepts with lean service concept in order to generate an effective methodology for achieving operational excellence. For instance, process management can be added to lean service for gaining service excellence.

- Future researches could emphasize more on after sales service industry as it hold a huge portion of the ever growing market.

- Although case study is very popular among the researchers but conducting this method over and over again will not bring robust conclusion unless and until a new method with strong empirical evidence joins with it.

\section{Note}

The author has included only the references mentioned in this article. The full list of articles studied is provided in the longer version of this article. The author will be more than happy to provide detailed information on request.

\section{References}

[1] Burnes, B. (2004). Managing Change: A strategic Approach to Organisational Dynamics. London: Financial Times.

[2] Kotter, J.R. (2007). Leading change - Why transformation efforts fail. Harvard Business Review, 85(1), 1-10.

[3] Maleyeff, J. (2006). Exploration of internal service systems using Lean principles. Management Decision, 44(5), 674-689.

[4] Womack, J., Jones, D. T. \& Roos, D. (1990). The Machine That Changed The World. Rawson Associates, New York, N.Y.

[5] Black, J. R., \& Miller, D. (2008). The Toyota way to healthcare excellence: Increase efficiency and improve quality with Lean. Chicago: Health Administration Press.

[6] Piercy, N. and Rich, N., 2009. High quality and low cost: The lean service centre. European Journal of Marketing, 43 (11-12), pp. 1477-1497.

[7] George, L. M. (2003) Lean Six Sigma For Service - How to Use Lean Speed and Six Sigma Quality to Improve Services and Transactions. USA: McGraw-Hill.
[8] Sarkar, D. (2011) Process Excellence Network [online], available:

$\mathrm{http}: / / w w w . p r o c e s s e x c e l l e n c e n e t w o r k . c o m / l e a n-s i x-s i g m a-b u s$ iness-transformation/articles/challenges-of-service-lean-imple mentation/ [accessed 09 May 2014].

[9] Tranfield, D., Denyer, D., \& Smart, P. (2003). Towards a methodology for developing evidenceinformed management knowledge by means of systematic review. British Journal of Management, 4(3), 207-222.

[10] Suárez-Barraza, M. F., Smith, T., \& Dahlgaard-Park, S. (2012) Lean Service: A literature analysis and classification. Total Quality Management \& Business Excellence, 23(3/4), 359-380.

[11] Womack, J.P. and Jones, D.T. (1996), Lean Thinking, Simon \& Schuster, New York, NY, pp. 90-8.

[12] Lipley, N. (2008). Lean times ahead. Nursing Management, $15(1), 1-3$.

[13] Al-Balushi S., Sohal A.S., Singh P.J., Al Hajri A., Al Farsi Y.M., Al Abri R., (2014) "Readiness factors for lean implementation in healthcare settings - a literature review", Journal of Health Organization and Management, Vol. 28, Iss: 2, pp. $135-153$.

[14] Dahlgaard, J.J., Kristensen, K., \& Kanji, G. (Eds.). (1995). A special issue on 'total quality in education'. Total Quality Management, 6(5\&6), 443-619.

[15] Kells, H.R. (1995). Creating a culture of evaluation and self-regulation in higher education organizations. Total Quality Management, 6(5/6), 457-467.

[16] Van Der Wiele, T. (1995). Quality management in a teaching organization. Total Quality Management, 6(5/6), 497-508.

[17] Emiliani, M.L. (2005). Using Kaizen to improve the graduate business school degree program. Quality Assurance in Education, 13(1), 37-52.

[18] Swank, C. K. (2003) The Lean service Machine. Harvard Business Review, 123-129.

[19] Greenwood, T., Bradford, M., \& Green, B. (2002). Becoming a lean enterprise: A tale of two firms. Strategic Finance, 84(5), 32-39.

[20] Hallowell R., (1996) "The relationships of customer satisfaction, customer loyalty, and profitability: an empirical study", International Journal of Service Industry Management, Vol. 7 Iss: 4, pp. $27-42$.

[21] Suarez-Barraza, M.F., \& Ramis-Pujol, J. (2008). Process standardisation and sustainable continuous improvement: A closer look at the application of ISO 9000 to Logron o City Council (Spain). International Journal of Quality and Standards, 1(2), 1-35.

[22] Bhatia, N., \& Drew, J. (2006). Applying lean production to the public sector. The McKinsey Quarterly, 3, 97-98.

[23] Aherne, J. (2007). Think lean. Nursing Management, 13(10), $13-15$.

[24] Logothetis, N. (1995). Towards a quality management of education. Total Quality Management, 6(5/6), 479-486.

[25] Dahlgaard, J.J., \& Ostergaard, P. (2000). TQM and lean thinking in higher education. Sinergie, Rapporti di Recerca, (9), 23-40. 
[26] Comm, C., \& Mathaisel, D. (2005). A case study in applying lean sustainability concepts to universities. International Journal of Sustainability in Higher Education, 6(2), 134-146.

[27] Reinhardt, K. (2007). Kaizen: A change for the better. Ground Support Worldwide, 15(8), 14-17.

[28] Taner, T. M. Sezen, B., \& Antony, J. (2007). An overview of six sigma applications in healthcare industry. International Journal of Health Care Quality Assurance, 20(4), 329-340.
[29] Radnor, Z., \& Boaden, R. (2008). Editorial: Lean in public services- panacea or paradox? Public and Money Management, 28(1), 3-7.

[30] Johnson, C., \& Martin, B. (1993). Applying global concepts to individual hotels at Park Inn International. International Journal Contemporary Hospitality Management, 5(5), 1-3.

[31] Karl E. Weick and Robert E. Quinn (1999). Organizational change and development. Annual Review of Psychology, Vol. 50, 361-386. 